\title{
The Influence of Productivity on Economic Welfare
}

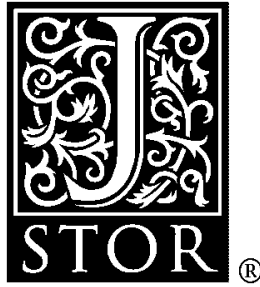

\section{J. Tinbergen}

The Economic Journal, Vol. 62, No. 245. (Mar., 1952), pp. 68-86.

Stable URL:

http://links.jstor.org/sici?sici=0013-0133\%28195203\%2962\%3A245\%3C68\%3ATIOPOE\%3E2.0.CO\%3B2-X

The Economic Journal is currently published by Royal Economic Society.

Your use of the JSTOR archive indicates your acceptance of JSTOR's Terms and Conditions of Use, available at

http://www.jstor.org/about/terms.html. JSTOR's Terms and Conditions of Use provides, in part, that unless you have obtained prior permission, you may not download an entire issue of a journal or multiple copies of articles, and you may use content in the JSTOR archive only for your personal, non-commercial use.

Please contact the publisher regarding any further use of this work. Publisher contact information may be obtained at http://www.jstor.org/journals/res.html.

Each copy of any part of a JSTOR transmission must contain the same copyright notice that appears on the screen or printed page of such transmission.

JSTOR is an independent not-for-profit organization dedicated to and preserving a digital archive of scholarly journals. For more information regarding JSTOR, please contact support@jstor.org. 


\section{THE INFLUENCE OF PRODUCTIVITY ON ECONOMIC WELFARE}

1. IT is a well-known old thesis that an increase in labour productivity leads to an increase in economic "welfare." Assuming for a while that the meaning of these two concepts is clear, we may say that the statement is correct for a Robinson Crusoe economy as we know it from our books. If Crusoe can get more products for the same effort, then probably he will shorten somewhat his working-day and get more products, and by doing so feel happier. The statement seems guaranteed for an economy : (i) without foreign trade, (ii) without working-hours regulations, (iii) without problems of capital scarcity and (iv) without monetary complications.

Many times already, however, doubt has arisen concerning the validity of that thesis. There are the old nineteenthcentury discussions on technological unemployment, and we all know their modern versions from the thirties. During the recent full-employment years the old optimism as to the consequences of increased productivity has been revived. Only quite recently new reasons for some qualifications have come up, among other things in connection with problems of capital scarcity and balance-of-payments equilibrium. I propose to reformulate some of these qualifications to the old thesis. This may prove to be of some use to practical policy in the field of productivity-furthering measures, now very much in the centre of public interest. In order to avoid misunderstanding I want to stress from the outset, however, that in its essence I consider the thesis as sound; we should be careful, however, not to apply it mechanically.

2. As is usual in economic science, much depends on a careful statement of the problem we want to consider. Discussing the influence of an increase in labour productivity on welfare first of all implies that we consider labour productivity as one of the data to the economy considered. This, I think, can be easily admitted. The next thing we have to do is to give a clear definition of what we understand by "welfare." This is already less simple. I do not propose to go into all the well-known questions of comparability of individual utilities; ${ }^{1}$ I want to

1 For a very clear summary of these problems, ef. Nancy Ruggles, " Recent Developments in the Theory of Marginal Cost Pricing," Review of Economic Studies, 1949-50, Vol. XVII (2), No. 43, pp. 107-26. 
take a "practical" point of view as my starting point. We may say, then, that perhaps the best single figure representing a nation's welfare is the value of its real expenditure on consumer and investment goods (to be written as $x$ in what follows). But welfare cannot be considered essentially as a one-dimensional concept; and at least some rough indications about the distribution of $x$ over certain groups of the population are needed in order to complement the figure $x$. I propose that two further figures are very useful : first, total real labour income $L^{\prime}$ as an indication of the distribution between the two big "classes" of society and, second, employment $a$ as an indication of the distribution between employed and unemployed.

The way in which these figures should be used in order to judge a change in the economy is different from the way in which we look at $x$. Here it is not so that $L^{\prime}$ and $a$ should be a maximum, but they may have optimum values. It is well known that any judgment on these figures is even more a matter of taste than a judgment on $x$. But serious declines in $L^{\prime}$ or $a$ generally should be a matter of concern.

It seems useful already to point to one feature of our main measure of welfare : real expenditure of a nation. This measure $x$ is not identical with the concept of the nation's product. For the product to become the nation's expenditure it is necessary to be exchanged, partially at least, at the world market. And this exchange, in dependence of the terms of trade prevailing, may change its value in a different way with one level of productivity than with another. An isolated increase in productivity will, generally speaking, worsen the country's terms of trade and hence the relation between real expenditure and product.

3. The third element in a careful statement of our problem consists in the set of hypotheses we introduce with regard to the structure of the economy considered. This concept we want to give a rather wide meaning. Not only have we to include in our concept of structure the particulars about the type of products and of productive agents characteristic of the country and the behaviour of its citizens as portrayed by the demand and supply functions, etc., but we have also to include hypotheses as to the governmental policy pursued, and, perhaps, as to what I want to call group behaviour. In modern economies the consequences of certain changes in data, such as an increase in productivity, not only ovoke individual reactions implied in the set of demand and supply relations, but also collective reactions as, e.g., govern- 
ment measures to protect the balance of payments, trade-union demands as to wages, demands by organised farmers as to farm prices, etc., and it is sometimes useful to distinguish between individual and collective policies.

Finally, when stating our problem we shall also have to pay attention to whether we think of short-run or of long-run reactions.

4. In terms which are customary nowadays this comes to saying that the consequences of an increase in labour productivity depend on the model we use. It is the purpose of this paper to present a number of models each of which may throw some light on our main problem. Some of these models (I, II and VIII) will be described in full; for the others the reader will be referred to other publications of the author. Before giving more details and a treatment of our problem, we may summarise in Table I some of the features of the models to be presented.

\section{TABLE I}

Summary of Features of Models Used ${ }^{1}$

\begin{tabular}{|c|c|c|c|c|c|c|c|c|c|}
\hline \multirow[b]{3}{*}{$\begin{array}{l}\dot{0} \\
\dot{2} \\
\dot{D} \\
\dot{0}\end{array}$} & \multirow{3}{*}{ 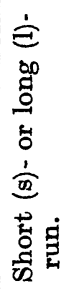 } & \multirow{3}{*}{ 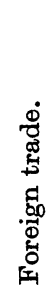 } & \multirow{3}{*}{ 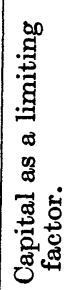 } & \multirow{3}{*}{ 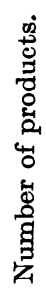 } & \multirow{3}{*}{ 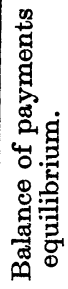 } & \multicolumn{4}{|c|}{ Government or Group policies. } \\
\hline & & & & & & \multicolumn{3}{|c|}{ Instruments. } & \multirow{2}{*}{ 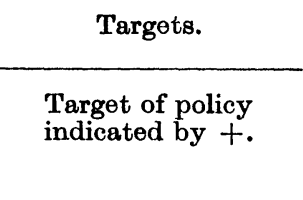 } \\
\hline & & & & & & 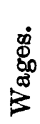 & 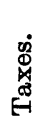 & 苟 & \\
\hline$I$ & 1 & - & + & 1 & & + & - & - & - \\
\hline II & 1 & + & - & 1 & + & - & - & - & • \\
\hline III & s & + & - & 1 & - & - & - & - & $\Leftrightarrow$. \\
\hline IV & s & + & - & 1 & + & + & - & - & "Social equ \\
\hline V & $\mathbf{s}$ & + & - & 1 & + & - & + & - & Equilibrium in balance \\
\hline VI & $\mathbf{s}$ & + & - & 1 & _ & - & + & - & Maintenance of em \\
\hline VII & $\mathbf{s}$ & + & - & 1 & - & - & - & + & ployment \\
\hline VIII & s & + & - & 2 & - & + & - & - & "Social equilibrium" \\
\hline
\end{tabular}

1 + means present; - means absent; . means does not apply.

5. Long-term, isolated-state, capital-shortage model (I). The first model to be discussed represents an attempt to portray the pure form of technological unemployment; in order to concentrate on this phenomenon the complications of short-termspending reactions and of international-trade connections have been eliminated. Adopting the style of the old models used in production theory (J. B. Clark, Douglas), a barter economy is assumed to exist, where one product for general use is produced 
by the combination of capital and labour. Capitalist and employer are the same person. The economy is a "multiple" of an optimum-size enterprise, working with a capital $k$ of infinite fluidity, technically adapted to the optimum method of production. The range of possible methods between which the employer may choose is indicated by a function $h(i)$, where $i$ is the "capital intensity" of a process, i.e., the amount of capital needed in order to employ one man according to that method, and $h$ is the productivity of that man. The curve $h=h(i)$ represents the "curve of the technical possibilities." The employer has to pay a real wage $l$ to each worker employed; this wage he considers as given (free competition between employers at the labour market). Indicating total production of the enterprise by $u$, the employer will choose $i$ such as to make his profit a maximum, i.e., $u-a l$; hence

$$
\frac{d u}{d i}-l \frac{d a}{d i}=0
$$

where $u=a h(i)$ and $a=\frac{k}{i}$, or

$$
\frac{d}{d i}\left\{\frac{k}{i} h(i)\right\}-l \frac{d}{d i} \frac{k}{i}=0
$$

It follows that

$$
h^{\prime}=\frac{h-l}{i} . \quad . \quad . \quad . \quad . \quad .
$$

meaning that the equilibrium point $E$ at the curve of technical possibilities (cf. Fig. 1) has a tangent passing through the point $P(0, l)$. The production of one man is indicated by $E Q$, of which $R Q$ is his wage. Total production is, as long as $k$ is constant, represented by $\operatorname{tg} \angle E O Q$.

The value of $i$, found from (5.1), determines how many workers $a=\frac{k}{i}$ will be absorbed. In its turn, $i$ depends on the curve $h(i)$, as well as on the value of $l$. Suppose that in an initial position there is full employment.

6. Suppose now that, with total capital $k$ per enterprise given, new technical possibilities are introduced, i.e., a new curve $h(i)$ develops. What will happen depends on the shape of that curve. As long as wages are constant, it may very well happen that not all workers can be absorbed. Adaptation of $l$ may be the consequence. But it may be that only at a wagerate zero or a negative wage-rate will all labour be absorbed. If only the curve of technical possibilities is sufficiently steep in 
its relevant parts, very strange things may happen (cf. Fig. 1, curve $\left.h_{1}(i)\right)$. The rather revolutionary changes in labour productivity represented by the change from curve $h$ to curve $h_{1}$ are characterised by two features. First, there is an increase in productivity for all capital intensities considered; and secondly, the increase is particularly large for ranges of capital intensity higher than those used so far. This means that if considerable investments are made, unprecedented increases in productivity are possible. The picture has been suggested by the development in the United States ${ }^{1}$ of new automats for

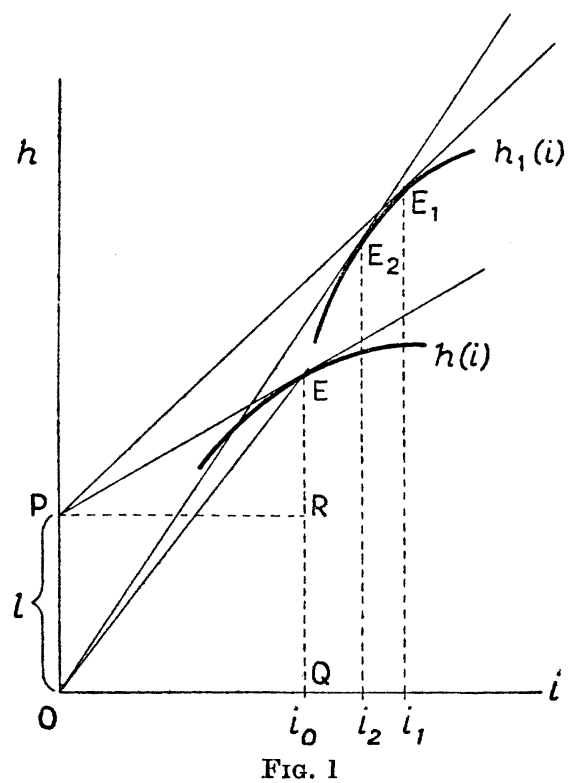

which these features apply. Our picture shows that if such a development was general, a shift of $E$ towards the right, i.e., unemployment, would be the consequence. The causes for it could be formulated as capital scarcity. The new methods (using automats) are, in our picture, of such a productivity that private employers will irresistibly be driven towards their application, whereas at the same time they are so capital-intensive that only part of the workers can be employed, even if wagerates are very low (point $E_{2}$ ).

What, then, happens to "welfare"? The first yardstick we proposed, total real expenditure, now coinciding with total production, may increase, even considerably, as in Fig. 1. But

1 F. L. Polak, De wentelgang der Wetenschap en de Maatschappij van morgen, Leiden, 1949 (Dutch). 
employment and total real labour income would fall considerably. The result for welfare would be dubious. It is even conceivable (cf. Fig. 2) that total production would fall and employment too. Here the result would be positively unfavourable for welfare.

7. Long-term open-economy model (II). As the next model we consider a nation with foreign trade, producing, with the aid of labour and organisation as productive agents, one product out of imported raw materials. The product is sold both at home and abroad. Monetary equilibrium, and hence equilibrium in the balance of payments, is maintained throughout. As the

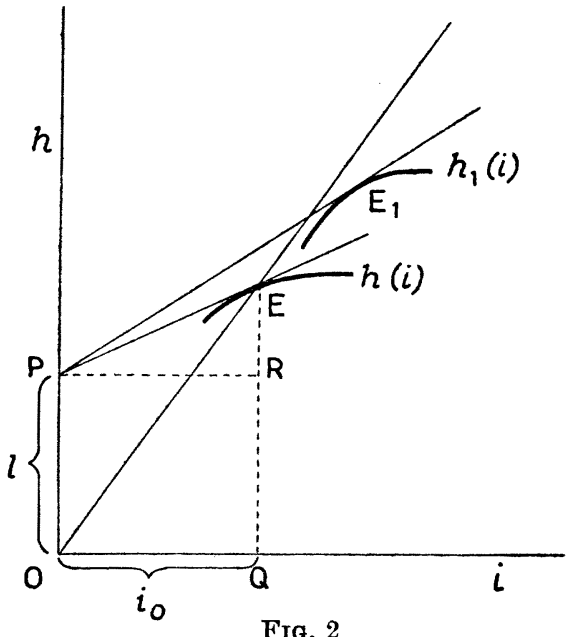

data of the economy we consider, apart from the usual structural data, the degree of labour productivity $h$. Provisionally the wage-rate $l$ and the autonomous profit margin $\pi_{0}$ (to be defined later) per unit of product are supposed to be independent of $h$. As the dependent variables of the system we consider: $Y$, national income in monetary units; $X$, national expenditure in monetary units; $v$, volume of production; $x$, real national expenditure; $p$, price level of product; $L^{\prime}$, real labour income ; $a$, volume of employment.

We compare two situations, an initial one, in which $Y=$ $X=y=x=p=a=h=l=1,1$ and one in which $h$ shows a variation $d h$. We propose to determine the corresponding variations in the dependent variables, in particular in $x, a$ and $L^{\prime}$, considered as measures of welfare.

1 Cf.the model used and described in some detail in J. Tinbergen, Econometrics, The Blakiston Co., Philadelphia, 1951, $\S 44 \mathrm{ff}$. 
Our structural relations are :

Income definition :

$$
Y=(1+\mu) y p-\mu y p^{s} . . . .
$$

Here $\mu$ represents the nation's import quota, which we consider constant (a loss of generality which may be shown not to be relevant for our purpose), and $\epsilon$ represents the price elasticity of imports with respect to the price level of the product.

Home demand equation :

$$
X=Y \cdot \quad \cdot \quad \cdot \quad \cdot \quad .
$$

Foreign demand equation :

$$
\mu y p^{-8}=\mu p^{1-\eta}
$$

Here the left-hand side represents the value of imports, which, as a consequence of balance-of-payments equilibrium, must be equal to the value of exports. The right-hand side represents the value of exports, which is equal to the price level $p$ multiplied by the demand function. The demand function $\mu p^{-\eta}$ shows an elasticity of $\eta$ with respect to prices; the constant factor $\mu$ is found by the condition of balance-of-payments equilibrium in the initial situation.

Supply equation :

$$
p=\pi_{0}+\pi_{1} \frac{l}{h}+\pi_{2}(y-1)+\pi_{3} \quad . \quad .
$$

This equation should be considered as an approximation for small variations in the variables. It expresses the price level as a sum of the following components :

(i) the autonomous part of the profit margin $\pi_{0}$;

(ii) labour costs, where $\pi_{1}$ represents the marginal wage quota;

(iii) the automatic part of the profit margin, assumed to vary linearly with the volume of production, where $\pi_{2}$ represents the price flexibility in the initial situation; and (iv) the import quota $\pi_{3}$, assumed constant in our problem.

Definition of home expenditure :

$$
X=x p \quad \cdot \quad \cdot \quad \cdot \quad \cdot \quad .
$$

Definition of employment :

$$
a=\frac{y}{h} \quad \cdot \quad \cdot \quad \cdot \quad \cdot \quad \cdot \quad
$$


Definition of real labour income :

$$
L^{\prime}=\Lambda \frac{y l}{h p}
$$

where $\Lambda$ represents the ratio of labour income to national income in the initial situation.

8. From these equations we deduce :

$$
\begin{aligned}
& d Y=(1+\mu)(d y+d p)-\mu d y-\mu \epsilon d p \\
& =d y+(1+\mu-\mu \epsilon) d p \\
& d X=d x+d p=X d Y \therefore d x=d y+\mu(1-\epsilon) d p \\
& \mu d y+\mu(\epsilon+\eta-1) d p=0 \\
& \therefore d y+(\epsilon+\eta-1) d p=0 \quad . \quad . \\
& \quad d p=\pi_{1}(d l-d h)+\pi_{2} d y+d \pi_{0} \\
& d L^{\prime}=\Lambda(d y+d l-d h-d p) . \\
& d a=d y-d h \quad . \quad . \quad . \quad .
\end{aligned}
$$

Equations (7.8) to (7.12) enable us to calculate $d x, d a, d L^{\prime}$, $d y$ and $d p$ as functions of the independent variations $d h, d l$ and $d \pi_{0}$. For our purpose only the expressions for $d x, d a$ and $d L^{\prime}$ in terms of $d h$ are relevant; hence we put $d l=d \pi_{0}=0$ and find :

$$
\begin{aligned}
d x & =\pi_{1} \frac{\eta-(1+\mu)(1-\epsilon)}{\pi_{2}(\epsilon+\eta-1)+1} d h \\
d a & =\frac{\left(\pi_{1}-\pi_{2}\right)(\epsilon+\eta-1)-1}{\pi_{2}(\epsilon+\eta-1)+1} d h . \\
d L^{\prime} & =\frac{\left(\pi_{1}-\pi_{2}\right)(\epsilon+\eta-1)+\pi_{1}-1}{\pi_{2}(\epsilon+\eta-1)+1} d h .
\end{aligned}
$$

It follows that the changes in each of our welfare indicators depend on the productivity change in a rather complicated way : the price elasticities of foreign trade, the price flexibility and the marginal labour quota entering into each relation, and the import quota in the first only. The signs of the coefficients will be different according to the numerical values of the data just enumerated. The reader may try several sets of values. Since the purpose of this model is to show some of the implications for countries with a considerable portion of foreign trade, we will substitute figures found to be a fair approximation to the situation in a small country like the Netherlands. It was found that $\pi_{1}=0.3 ; \pi_{2}=0.1 ; \eta=2 ; \epsilon=0.3$ and $\mu=0.4$, leading to the formulæ: $d x=0.3 d h ; d a=-0.7 d h ; d L^{\prime}=-0.4 d h$.

Total real expenditure therefore increases, but employment, as well as real wage income, decrease with increasing productivity. 
The influence on "welfare" therefore depends on how heavily the decrease in employment and labour income count for us. Moreover, it is interesting to note that even $d x<0$ for $0.7 \eta+\epsilon<1$, i.e., for values of the elasticities considerably less stringent than the well-known "critical values" in the unstable balance-ofpayments case. ${ }^{1}$

9. Short-run open-economy models (III-VIII). The models to be discussed in what follows are all short-run models in the sense that expenditures are supposed to react on income changes in the Keynesian way. This means that equation (7.2) of the previous model is replaced by a more general one :

$$
x=L^{\prime}+(1-\sigma) Z^{\prime}+c^{\prime} \text {. . . . }
$$

where $Z^{\prime}$ is real entrepreneurial income, $\sigma$ their " marginal propensity not to spend " and $c^{\prime}$ a constant; $c^{\prime}$ depends on the initial situation. This model has been used for other purposes and described elsewhere. ${ }^{2}$ Apart from slight differences that are irrelevant for the present purpose, the other relations in it are based on the same assumptions as in Model II.

In some of the versions there are, however, added one or two further variables representing instruments of economie policy that may possibly interfere with our problem and contribute to the consequences of an increase in labour productivity. In Model III no such additional instruments are considered, but since balance-of-payments equilibrium is no longer presupposed, the deficit $D$ on current account of this balance is an additional symbol used.

Dealing with the equations in the same way as in the previous model (II) and taking $\sigma=0 \cdot 3$, we find :

$$
\begin{array}{rllllll}
d x & =-0 \cdot 1(d h-d l) & . & . & . & . & . \\
d a & =-0.9 d h-0 \cdot 1 d l & . & . & . & . & . \\
d L^{\prime} & =-0 \cdot 6(d h-d l) & . & . & . & . & . \\
d D & =-0 \cdot 1(d h-d l) & . & . & . & . & .
\end{array}
$$

The choice of $\sigma$ is based upon the assumption that additional income is heavily taxed and government expenditure only partially. reacts on an increase in tax receipts. Taking $\sigma=0.2$ or 0.4 does not essentially change our results.

Comparing these results with those obtained for Model II and assuming, as a start, that wage-rates do not change $(d l=0)$,

1 Cf. e.g., G. Stuvel, The Exchange Stability Problem, Leiden, 1950, where all previous authors are also cited.

2 Cf. note 1 on p. 73. 
we see that again the influence of $h$ on $a$ and $L^{\prime}$ is negative. The balance-of-payments deficit appears to react in the "classical" way : decreasing with an increase in productivity.

In addition, we now find that even the influence on $x$ is slightly negative. This is evidently due to the tendency, now assumed, to hoard part of an additional income $Z^{\prime}$. Given the fact that workers' income declines and non-workers hoard part of the increase, the possibility arises of a decrease in total expenditure; and with the numerical values of our coefficients this appears actually to happen.

In this case the negative effect on total real expenditure, explained by the tendency to hoard, is the more remarkable, as the influence of $h$ on the volume of production $y$ is easily found to be positive; since $d y=d a+d h$, we have

$$
d y=0 \cdot 1(d h-d l) \quad . \quad . \quad .
$$

Here we have a clear example of the adverse influence of the terms of trade : the increase in $h$ causes prices to go down, and this fall explains the divergency between $d y$ and $d x$.

Our conclusion must be that an increase in labour productivity in this model turns out to be detrimental to welfare, although the effect on the balance of payments appears to be slightly favourable.

10. Wages fully responding to productivity increases (Model IV). The first alternative on Model III we shall deal with assumes that wages are not kept constant, but move along with the change in productivity; hence $d l=d h$. This behaviour of wages may be interpreted as the realisation of "social equilibrium," if by that phrase we mean the maintenance of the distribution of national income between labour and non-labour income. In fact, it may be easily seen that only by this wage policy will distribution remain unaltered. This assumption leads us to the remarkable result that:

and

$$
d x=d y=d L^{\prime}=d D=0 . \quad .
$$

This result may also be obtained in a verbal and more general way. ${ }^{1}$ The only assumptions to be made are :

(a) The price level depends on wage-rates and productivity only as far as the ratio between these two variables changes; in addition, it depends on the volume of production.

1 Cf. J. Tinbergen, "The Significance of Wage Policy for Employment," International Economic Papers (I), 1951. 
(b) The volume and the value of exports depend on wage-rates and productivity only through their dependence of prices.

(c) With constant foreign prices, the volume and value of imports depend only on the volume of production and the price level of national products.

(d) National income is a function of national expenditure, exports and imports.

(e) National expenditure is a function of national income, labour income and the price level.

(f) Labour income is the product of the volume of production and labour costs per unit of product (which equal the ratio between the wage-rate and productivity).

From these assumptions, which together with some definitions represent a sufficient number of relations to determine, among other things, the volume of production $y$, total real expenditure $x$, real labour income $L^{\prime}$ and the balance-of-payments deficit $D$ as functions of productivity and the wage-rate, it will be found that $y, x, L^{\prime}$ and $D$ depend only on the ratio of $l$ and $h$ and, besides that, in no other way on $l$ and $h$. Any changes in $l$ and $h$ that do not affect their ratio will not change, therefore, $y, x$, $L^{\prime}$ and $D$, as indicated by (10.1). Since, in addition, $a=\frac{y}{h}$, $d a=-d h$ as long as $d l=d h$.

The result for our topic is that with this wage policy an increase in productivity will not affect $x, L^{\prime}$ or $D$ and adversely affect employment. The result might be interpreted by stating that national welfare of an open economy cannot increase if exports do not increase and that the assumed wage policy prevents this possible effect of an increase in productivity from materialising.

11. Tax policy in order to maintain balance-of-payments equilibrium (Model V). Introducing now, as an additional instrument of economic policy, a possible increase in indirect taxes and assuming this instrument to be used in order to maintain balance-of-payments equilibrium, we obtain relations ${ }^{1}$ in which the change in the rate $\tau$ of indirect taxes appears as an additional variable :

$$
\begin{aligned}
& d x=-0 \cdot 1(d h-d l)-2 \cdot 0 d \tau . . . \\
& d a=-0.9 d h-0.1 d l-1.3 d \tau . \quad . \quad \text {. } \\
& d L^{\prime}=-0 \cdot 6(d h-d l)-2 \cdot 1 d \tau . \quad . \quad . \\
& d D=-0 \cdot 1(d h-d l)-0 \cdot 7 d \tau \text {. . . . } \\
& 1 \text { Loc. cit. }
\end{aligned}
$$


The first two terms at the right-hand side are the same as in equations (9.2) to (9.5).

Assuming that again wage-rates will not be changed, but that tax rates will be altered in such a way as to maintain balance-of-payments equilibrium, we have to find $d \tau$ from the relation

or

$$
0=d D=-0 \cdot 1 d h-0 \cdot 7 d \tau
$$

leading to :

$$
\begin{aligned}
d \tau & =-0 \cdot 15 d h \\
d x & =0 \cdot 2 d h \\
d a & =-0 \cdot 7 d h \\
d L^{\prime} & =-0 \cdot 3 d h
\end{aligned}
$$

This change in policy appears to bring about a positive influence of labour productivity on real expenditure, leaving us still, however, with a negative influence on employment and real workers' income.

12. Tax policy in order to maintain employment (Model VI). Let us now suppose that tax policy is not used in order to maintain balance-of-payments equilibrium but in order to maintain employment. This comes to choosing, in formulæ (11.1) to (11.4), $\tau$ so as to make $d a=0$ (taking still $d l=0$ ). The results are :

and

$$
\begin{aligned}
& d \tau=-0 \cdot 7 d h . \quad . \quad . \quad . \quad . \quad . \\
& d x=1 \cdot 3 d h \quad \cdot \quad \cdot \quad \cdot \quad \cdot \quad \cdot \\
& d L^{\prime}=0 \cdot 7 d h \quad \text {. . . . . . } \\
& d D=0.4 d h \quad \text {. . . . . . }
\end{aligned}
$$

"Welfare" in our sense will now be favourably influenced to a slight degree but at the expense of a considerable increase in the balance-of-payments deficit. Similar results would have been obtained if we had taken $d l=d h$.

13. Price policy in order to maintain employment (Model VII). Similar calculations were made with still another additional instrument, viz., by introducing price policy (profit-margin regulations) as a means of maintaining employment. With this instrument as an additional variable $\pi_{0}$, the formulæ (9.2) to (9.5) become :

$$
\begin{aligned}
& d x=-0 \cdot 1(d h-d l)-0.9 d \pi_{0} \quad . \quad . \quad . \\
& d a=-0.9 d h-0 \cdot 1 d l-1 \cdot 1 d \pi_{0} . . . \\
& d L^{\prime}=-0.6(d h-d l)-2 \cdot 0 d \pi_{0} \quad . \quad . \quad . \\
& d D=-0 \cdot 1(d h-d l)-0 \cdot 0 d \pi_{0} \quad . \quad . \quad .
\end{aligned}
$$


Choosing $d \pi_{0}$ so as to make $d a$ vanish we get :

leading to :

$$
\begin{array}{lllllll}
d \pi_{0} & =-0 \cdot 8 d h & . & . & . & . & . \\
d x= & =0 \cdot 6 d h & . & . & . & . & . \\
d L^{\prime} & =+d h & . & . & . & . & . \\
d D & =-0.1 d h & . & . & . & . & .
\end{array}
$$

This version appears to be favourable to welfare in the various aspects used so far and to the balance of payments. But here, as could be expected, it is non-workers that have to bear the burden, and again the effect is questionable.

14. Two-industry version of short-term model (Model VIII). The models so far analysed have shown us that the influence of productivity on economic welfare and the balance of payments is by no means as unambiguous as is often believed. It very much depends on a number of circumstances whether an increase in productivity has or has not a favourable effect-however the term favourable be interpreted. This conclusion is of some importance, as has been pointed out already in section 1 , for present-day economic policy in a number of countries, since there is a strong tendency to advocate increases in productivity in a general way. It would appear that at least certain qualifications might be useful and that, perhaps, a policy of furthering productivity deserves to be directed towards specific industries in order to have a maximum of success. Some of the adverse reactions so far detected probably work out in a more pronounced way in one and in a less pronounced way in another type of industry; this applies, e.g., to the capital-shortage argument, whereas, on the other hand, the significance for foreign trade also varies considerably between one industry and the other.

For these reasons the macro-economic approach of the preceding sections cannot be the only basis of devices for practical policy. Divergencies between industries are ruled out beforehand in these models. They may have made us cautious vis-à-vis too simple ideas about the desirability of a general increase in productivity in one country, but they cannot show us the way towards alternative policies. Micro-economic models will be necessary; but we know by now that their handling is no simple affair. There seems to be some wisdom in a modest start, and this is why $I$ propose only to contrast the previous models to the simplest conceivable alternative in this connection : a two industry model, leaving it to others more courageous than $I$ to expand the number of industries. 
In order to find out in exactly what way the two-industry version leads to results different from a one-industry version we will discuss one and the same problem in both ways; in order to reduce the problem to its simplest kernel we will even simplify the one-industry model still further. The problem to solve will be the following: suppose we want (i) to maintain employment, (ii) to maintain social equilibrium as defined in section 10 and (iii) to restore equilibrium in the balance of payments, how have we to vary labour productivity?

The reader will observe that by posing this problem I have shifted from a problem of explanation to a problem of policy, or, as we now say, to a "decision model" (Frisch). This will probably accentuate some of our findings so far in a useful way.

We will use Model II of section 7 with the exception of the hypothesis of monetary equilibrium, meaning that we assume a more general spending reaction. Moreover, we will simplify our supply equation by taking $\pi_{2}=0$ (which does not influence our results very much). Since the balance-of-payments deficit $D=$ value of imports - value of exports, we find from (7.3) and (7.9) :

$$
d D=\mu d y+\mu(\epsilon+\eta-1) d p .
$$

and from (7.4) and (7.10):

$$
d p=\pi_{1}(d l-d h)
$$

ruling out the possibility of changes in $\pi_{0}$.

For our problem it is useful to replace $d y$ by $d a+d h$ (cf. 7.12) in equation (14.1). The condition of social equilibrium may be written as $\frac{d p}{p-\pi_{3}}=\frac{d l-d h}{l / h}$ or

$$
d p=\lambda(d l-d h)
$$

where $\lambda$ is the initial value of $\frac{p-\pi_{3}}{l / h}=0 \cdot 7$.

Equations (14.1) to (14.3) are then three equations enabling us to find the three political instruments $d l, d h$ and $d p$ when the three targets $d a, \lambda$ and $d D$ are given. The solution is easy: we find $d p=0, d l=d h$ and $\mu d h=d D$. The latter result tells us that in order to reduce $D$ we have to reduce $h$, and therefore represents some of the paradoxical conclusions reached so far.

15. This set-up we will now refine by considering two industries instead of one. By so doing we shall meet some of the more general difficulties of "micronising" macro-models; but we shall not go into this side more systematically.

No. 245-VOL. LXII. 
We have now to deal with two branches, each of them characterised by their own $a, y, x, e, h, p, \mu$ and $\pi$, which we shall distinguish by super-scripts 1 and 2 . Of these, the $h \mathrm{~s}$ and the $p \mathrm{~s}$ will remain index-numbers with an initial value of 1 , but the $a \mathrm{~s}, y \mathrm{~s}, x \mathrm{~s}$ and $e \mathrm{~s}$ are supposed to add up to the corresponding macro concepts. We shall assume wage-rates and export elasticities to be the same in the two industries and therefore maintain our symbols $l$ and $\epsilon$. As targets we consider :

(i) to maintain employment $a^{1}$ and $a^{2}$ in the two industries, i.e., $d a^{1}=d a^{2}=0$;

(ii) to maintain social equilibrium, i.e., $d p=\lambda(d l-d h)$, where $h$ and $p$ now represent weighted averages of $h^{1}, h^{2}$ and $p^{1}, p^{2}$, to be defined later; and

(iii) to restore equilibrium in the balance of payments, i.e., to give a certain negative value to $d D$.

Our unknowns are $p^{1}, p^{2}, l, h^{1}$ and $h^{2}$.

Our equations will be the analogues to (14.1) to (14.3); but we want more equations, since we have more unknowns. On the other hand, the existence of more than one industry also implies the existence of more relations.

The following equations are easily found :

$$
\begin{aligned}
& d D=\mu^{1} d y^{1}+\mu^{2} d y^{2}-d e^{1}-e^{1} d p^{1}-d e^{2}-e^{2} d p^{2} . \\
& d p=\frac{v^{1} d p^{1}+v^{2} d p^{2}}{v^{1}+v^{2}}=\frac{v^{1} \pi_{1}{ }^{1}\left(d l-d h^{1}\right)+v^{2} \pi_{1}{ }^{2}(d l-d h)}{v^{1}+v^{2}} \\
& d p^{1}=\pi_{1}{ }^{1}\left(d l-d h^{1}\right) \\
& d p^{2}=\pi_{1}^{2}\left(d l-d h^{2}\right) \text {. } \\
& d e^{1}=-e^{1} \epsilon d p^{1} \\
& d e^{2}=-e^{2} \epsilon d p^{2} \\
& \frac{d y^{1}}{y^{1}}=\frac{d a^{1}}{a^{1}}+\frac{d h^{1}}{h^{1}} \text {. } \\
& \frac{d y^{2}}{y^{2}}=\frac{d a^{2}}{a^{2}}+\frac{d h^{2}}{h^{2}} \text {. }
\end{aligned}
$$

In these equations $v^{1}$ and $v^{2}$, used as weights for $p^{1}$ and $p^{2}$, are the volumes of gross production, as distinguished from the volumes of net production $y^{1}$ and $y^{2}$; for an industry with a higher import quota $v^{2}$ is relatively larger than $y^{2}$; but we assume that $v^{1}$ varies proportionally to $y^{1}$ and $v^{2}$ to $y^{2}$. Further $h^{1}=h^{2}=1$ and $d a^{1}=d a^{2}=0$.

The above eight equations are not sufficient in number to yield us all the nine unknowns $d y^{1}, d y^{2}, d e^{1}, d e^{2}, d p^{1}, d p^{2}, d h^{1}$, 
$d h^{2}$ and $d l$. It is necessary now to give some attention to the variables $d x^{1}$ and $d x^{2}$; and their role is understood most easily if we also consider $d v^{1}$ and $d v^{2}$. Hence, four new unknowns and five more equations are introduced. Four of them give no trouble :

$$
\begin{aligned}
& d v^{1}=d x^{1}+d e^{1} \\
& d y^{2}=d x^{2}+d e^{2}
\end{aligned}
$$

The fifth has to tell something about the relation between $d x^{1}$ and $d x^{2}$. This was not necessary in our one-industry model, since total real expenditure $d x$ depends on $d y$ through the spending relation which is no longer free once we make a certain assumption on the balance of payments : the deficit.on that balance is identical with the monetary deficit in internal spending. In the two-industry model, however, the distribution of $d x$ over $d x^{1}$ and $d x^{2}$ also comes in, and that is not implied in any of the other relations. This distribution will, generally speaking, depend on the relative prices of goods 1 and 2. Only as a limiting case may we assume, which we will do for simplicity, that it is independent of prices. Next, the distribution will depend on the size of $x^{1}$ and $x^{2}$; there will be a tendency for $d x^{1}$ and $d x^{2}$ to be proportional to $x^{1}$ and $x^{2}$. But a third tendency is present, determined by income elasticities of $x^{1}$ and $x^{2}$; the higher the elasticity of $x^{1}$, the higher $d x^{1}$. Putting

$$
\frac{d x^{1}}{x^{1}}=\rho \frac{d x^{2}}{x^{2}} \text {. . . . . . }
$$

$\rho$ represents the ratios of the income elasticities for $x^{1}$ and $x^{2}$.

16. We are now able to solve our equations. Leaving the algebra to the reader and using the relations $\left(1+\mu^{1}\right) y^{1}=v^{1}=$ $x^{1}+e^{1}$ and $\left(1+\mu^{2}\right) y^{2}=v^{2}=x^{2}+e^{2}$, we may first reduce our system to three equations in $d l, d h^{1}$ and $d h^{2}$ :

$$
\begin{gathered}
x^{2}\left\{\left(x^{1}+e^{1}\right) d h^{1}+e^{1} \epsilon \pi_{1}{ }^{1}\left(d l-d h^{1}\right)\right\}=\rho x^{1}\left\{\left(x^{2}+e^{2}\right) d h^{2}+\right. \\
\left.e^{2} \epsilon \pi_{1}{ }^{2}\left(d l-d h^{2}\right)\right\} \cdot \\
\left(x^{1}+e^{1}\right) \pi_{1}{ }^{1}\left(d l-d h^{1}\right)+\left(x^{2}+e^{2}\right) \pi_{1}{ }^{2}\left(d l-d h^{2}\right)=0 . \\
\frac{\mu^{1}}{1+\mu^{1}}\left(x^{1}+e^{1}\right) d h^{1}+\frac{\mu^{2}}{1+\mu^{2}}\left(x^{2}+e^{2}\right) d h^{2}+(\epsilon-1)\left\{e^{1} \pi_{1}{ }^{1}(d l-\right. \\
\left.\left.d h^{1}\right)+e^{2} \pi_{1}{ }^{2}\left(d l-d h^{2}\right)\right\}=d D .
\end{gathered}
$$


Equation (16.2) enables us to express $d l$ in terms of $d h^{1}$ and $d h^{2}$ :

where

$$
\left(b^{1}+b^{2}\right) d l=b^{1} d h^{1}+b^{2} d h^{2} . \quad .
$$

$$
b^{1}=\pi_{1}{ }^{1}\left(x^{1}+e^{1}\right) \text { and } b^{2}=\pi_{1}{ }^{2}\left(x^{2}+e^{2}\right) .
$$

representing total wages in the initial situation in branches 1 and 2, respectively. Substituting (16.4) into (16.1), we find $d h^{1} / d h^{2}$ :

$\frac{d h^{1}}{d h^{2}}=\frac{\rho\left(x^{2}+e^{2}\right) x^{1}-E\left\{x^{2} e^{1}\left(x^{2}+e^{2}\right)+\rho x^{1} e^{2}\left(x^{1}+e^{1}\right)\right\}}{\left(x^{1}+e^{1}\right) x^{2}-E\left\{x^{2} e^{1}\left(x^{2}+e^{2}\right)+\rho x^{1} x^{2}\left(x^{1}+e^{1}\right)\right\}}$. where $E=\frac{\epsilon \pi_{1}^{1} \pi_{1}^{2}}{b^{1}+b^{2}}$.

Finally, we may find, e.g., $d h^{1}$ from a substitution of (16.6) into (16.3).

It would lead us too far to discuss all the implications of the solutions. We want to stress, however, the following points :

A. The example clearly shows how rapidly matters become more complicated with an increase in the number of branches.

B. It may be shown that not only different values for $d h^{1}$ and $d h^{2}$ will be found, but that even different signs of $d h^{1}$ and $d h^{2}$ are possible. According to formula (16.6), this depends on the values of $x^{1}, x^{2}, e^{1}, e^{2}, \rho$ and $E$, i.e., on the sales composition of each of the industries, on the ratio of their income elasticities $\rho$, on the price elasticity $\epsilon$ (taken equal for both industries) and the product of their labour quota $\pi_{1}{ }^{1}$ and $\pi_{1}{ }^{2}$. Taking, to begin with, $\rho=1, \epsilon=2, b^{1}+b^{2}=0.5$ and $\pi_{1}{ }^{1} \pi_{1}{ }^{2}=0.09$, we find for $d h^{1} / d h^{2}$ :

\section{TABLE II}

Two-industry Model. Values for $\mathrm{dh}^{1} / \mathrm{dh}^{2}$ with

\begin{tabular}{|c|c|c|c|c|c|}
\hline$x^{1}$ & 0. & 0.1 & 0.2 & 0.3 & 0.4 . \\
\hline $\begin{array}{l}0 \\
0 \cdot 1 \\
0 \cdot 2 \\
0 \cdot 3 \\
0 \cdot 4 \\
0 \cdot 5\end{array}$ & $\begin{array}{c}\text { indet. } \\
1.5 \\
1.5 \\
1.6 \\
1.7 \\
1.9\end{array}$ & $\begin{array}{r}-0.9 \\
0.6 \\
0.9 \\
1.1 \\
1.2 \\
1.4\end{array}$ & $\begin{array}{r}-0.8 \\
0.2 \\
0.5 \\
0.7 \\
0.9 \\
1.0\end{array}$ & $\begin{array}{r}-0.7 \\
-0.0 \\
0.3 \\
0.5 \\
0.6 \\
0.7\end{array}$ & $\begin{array}{r}-0.6 \\
-0.1 \\
0.2 \\
0.3 \\
0.4 \\
0.5\end{array}$ \\
\hline
\end{tabular}
$\rho=1, \epsilon=2, b^{1}+b^{2}=0.5$ and $\pi^{1}{ }_{1} \pi^{2}{ }_{1}=0.09$

Evidently the negative sign for $d h^{1} / d h^{2}$ occurs here only if $x^{1}$ is very small, i.e., if industry 1 is mainly an export industry. It is clear that in that case indeed an increase in productivity will yield a positive contribution to the balance of payments. 
From the structure of the formula for $d h^{1} / d h^{2}$ it is also clear that with higher values for $E$, i.e., for higher export elasticities as well as for higher labour quota, negative values for $d h^{1} / d h^{2}$ will occur more frequently. The same is true for lower values of $\rho$, i.e., if industry 1 shows a relatively lower income elasticity of home demand than industry 2.

C. On the other hand, it is remarkable that $\mu^{1}$ and $\mu^{2}$, the import quota, do not directly influence the value of $d h^{1} / d h^{2}$; they do not occur in formula (16.6). This statement should, however, be supplemented by the consideration that $\mu^{1}$ and $\mu^{2}$ are not completely free, once that the $x$ and the $e$ are given. Since, in our system of units, $y=1$ or $y^{1}+y^{2}=0$, we have :

$$
\frac{x^{1}+e^{1}}{1+\mu^{1}}+\frac{x^{2}+e^{2}}{1+\mu^{2}}=1 \quad \text {. . . }
$$

meaning that $\mu^{1}$ and $\mu^{2}$ are situated on an equilateral hyperbola. As a consequence of boundary conditions for the $x$ and $e$ (all of them should be positive), not all values of $\mu^{1}$ and $\mu^{2}$ are permitted.

D. The condition for $d h^{1}$ to be equal to $d h^{2}$ is also easily found; it is

$$
\rho\left(x^{2}+e^{2}\right) x^{1}=\left(x^{1}+e^{1}\right) x^{2} \quad . \quad .
$$

In this case there is no need for a micro-model.

17. Summary. Let us try to summarise our findings. The old thesis that an increase in productivity leads to an increase in welfare should not be misunderstood. Not under all circumstances does it lead to consequences that are in all respects attractive. In a number of cases the consequences are definitely mixed; some of them favourable, others unfavourable. It does not always entail an increase in total real expenditure; nor does it always yield an increase in real workers' income. Often it reduces the volume of employment. If it acts favourably on all these aspects of welfare it may deteriorate the balance of payments or real non-workers' income.

Of course, some of these statements have an element of selfevidence. If we find, in Model III, that $x, a$ and $L^{\prime}$ all diminish but the balance of payments improves, one may object that this balance-of-payments surplus should somehow be added to the results. This is, to some extent, correct. But on the other hand, the tendency to hoarding which is the reason for the balance-of-payments surplus does cause total real expenditure, and hence presumably consumption, to go down, be it only temporarily. 
Another objection may be that a decline in employment is in fact an element of welfare, since it represents leisure, and that an increase in leisure is one of the natural ways of enjoying the advantages of increased productivity. This is also in some sense true; here the difficulty is that in present-day society the decline in employment is often borne by a small group of unemployed and if so is certainly an evil. A final remark may be that we studied only isolated increases in productivity in one country and that some of the adverse effects may vanish if all countries show an increase in productivity at the same time. This again does not help countries now summoned to raise productivity more than others.

In fact it may be said that an increase in productivity in one country (without an increase in the other countries)-just as an increase in productivity in one firm-to a large extent comes to the advantage of the buyers, i.e. the other countries.

As I said already, the interpretation of this study should nevertheless not be that increases in productivity are of no use. They decidedly are, but they should at the same time be wellselected and well-directed increases in productivity.

J. TINBergen

The Hague. 
http://www.jstor.org

\section{LINKED CITATIONS \\ - Page 1 of 1 -}

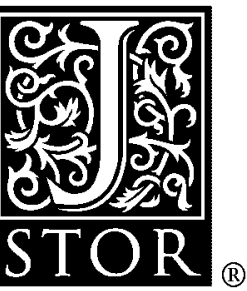

You have printed the following article:

The Influence of Productivity on Economic Welfare

$\mathrm{J}$. Tinbergen

The Economic Journal, Vol. 62, No. 245. (Mar., 1952), pp. 68-86.

Stable URL:

http://links.jstor.org/sici?sici=0013-0133\%28195203\%2962\%3A245\%3C68\%3ATIOPOE\%3E2.0.CO\%3B2-X

This article references the following linked citations. If you are trying to access articles from an off-campus location, you may be required to first logon via your library web site to access JSTOR. Please visit your library's website or contact a librarian to learn about options for remote access to JSTOR.

\section{[Footnotes]}

\footnotetext{
${ }^{1}$ Recent Developments in the Theory of Marginal Cost Pricing

Nancy Ruggles

The Review of Economic Studies, Vol. 17, No. 2. (1949 - 1950), pp. 107-126.

Stable URL:

http://links.jstor.org/sici?sici=0034-6527\%281949\%2F1950\%2917\%3A2\%3C107\%3ARDITTO\%3E2.0.CO\%3B2-O
}

NOTE: The reference numbering from the original has been maintained in this citation list. 